\title{
RANDOM FIXED POINT THEOREMS FOR LOWER SEMICONTINUOUS CONDENSING RANDOM OPERATORS
}

\author{
MONICA PATRICHE \\ University of Bucharest, Faculty of Mathematics and Computer Science \\ 14 Academiei Street, Bucharest, Romania \\ E-mail: monica.patriche@yahoo.com
}

\begin{abstract}
In this paper, we study the existence of the random fixed points for lower semicontinuous condensing random operators defined on Banach spaces. Our results extend corresponding ones present in literature.
\end{abstract}

Key Words and Phrases: random fixed point theorem, lower semicontinuous operator, condensing operator.

2010 Mathematics Subject Classification: 91B52, 91B50, 91A80, 47H10.

\section{REFERENCES}

[1] R.P. Agarwal, J. H. Dshalalow, D. O'Regan, Fixed point theory for Mönch-type maps defined on closed subsets of Fréchet spaces: the projective limit approach, International J. Math. Mathematical Sciences, 2005, 2775-2782.

[2] R.P. Agarwal, D. O'Regan, Random fixed point theorems and Leray-Schauder alternatives for $U_{c}^{k}$ maps, Commun. Korean Math. Soc., 20(2005), 299-310.

[3] R.P. Agarwal, M. Frigon, D. O'Regan, A survey of recent fixed point theory in Fréchet spaces, Nonlinear Analysis and Applications: dedicated to V. Lakshmikantham on his 80th birthday, Kluwer Acad. Publ. 1, 2(2003), 75-88.

[4] R.P. Agarwal, D. O'Regan, M. Sambandham, Random fixed point theoremes for multivalued countably condensing random operators, Stochastic Anal. Appl., 20(2002), 1157-1168.

[5] G. Debreu, Integration of correspondences, Proc. Fifth Berkely Symp. Math. Statist. Prob., University of California Press, 2(1966), 351-372.

[6] R. Fierro, C. Martinez, C.H. Morales, Fixed point theorems for random lower semicontinuous mappings, Fixed Point Theory and Applications, 2009, Article ID 584178, doi:10.1155/2009/584178.

[7] R. Fierro, C. Martinez, C.H. Morales, Random coincidence theorems and applications, J. Math. Anal. Appl., 378(2011), 213-219.

[8] R. Fierro, C. Martinez, E. Orellana, Weak conditions for existence of random fixed points. Fixed Point Theory, 12(2011), no. 1, 83-90.

[9] K. Kuratowski, C. Ryll-Nardzewski, A general theorem on selectors, Bulletin de l'Académie Polonaise des Sciences, Série des Sciences Mathématiques, Astronomiques et Physiques, 13(1965), 397-403.

[10] T.A. Lazar, A. Petruşel, Shahzad, Fixed points for non-self operators and domain invariance theorems, Nonlinear Anal., 70(2009), 117-125. 
[11] E. Michael, Continuous selection, Annals of Math., 63(1956), 361-382.

[12] D. O'Regan, An essential map approach for multimaps defined on closed subsets of Fréchet spaces, Applicable Anal., 85(2006), 503-513.

[13] D. O'Regan D., R.P. Agarwal, Fixed point theory for admissible multimaps defined on closed subsets of Fréchet spaces, J. Math. Anal. Appl., 277(2003), 438-445.

[14] D. O'Regan, N. Shahzad, Random approximation and random fixed point theory for random non-self multimaps, New Zealand J. Math., 34(2005), no. 2, 103-123.

[15] D. O'Regan, N. Shahzad, Random and deterministic fixed point and approximation results for countably 1-set-contractive multimaps, Appl. Anal., 82(2003), no. 11, 1055-1084.

[16] M. Patriche, A new fixed-point theorem and its applications in the equilibrium theory, Fixed Point Theory, 1(2009), 159-171.

[17] M. Patriche, Equilibrium in Games and Competitive Economies, The Publishing House of the Romanian Academy, Bucharest, 2011.

[18] M. Patriche, Fixed point theorems for nonconvex valued correspondences and applications in game theory, Fixed Point Theory 14(2013), no. 2, 435-446.

[19] M. Patriche, Fixed point theorems and applications in theory of games, Fixed Point Theory, 15(2014), no. 1, 199-212.

[20] M. Patriche, Random fixed point theorems under mild continuity assumptions, Fixed Point Theory Appl., 2014, 2014:89, doi:10.1186/1687-1812-2014-89.

[21] A. Petruşel, Multivalued operators and fixed points, Pure Math. Appl., 11(2000), 361-368.

[22] A. Petruşel, I.A. Rus, Fixed point theory of multivalued operators on a set with two metrics, Fixed Point Theory 8(2007), 97-104.

[23] N. Shahzad, Random fixed points of set-valued maps, Nonlinear Anal.,45(2001), 689-692.

[24] N. Shahzad, Random fixed point theorems for 1-set-contractive multivalued random maps, Stochastic Anal. Appl., 19(2001), no. 5, 857-862.

[25] N. Shahzad, Random fixed points of K-set and pseudo-contractive random maps, Nonlinear Anal., 57(2004), 173-181.

[26] N. Shahzad, N. Hussain, Deterministic and random coincidence point results for f-nonexpansive maps, J. Math. Anal. Appl., 323(2006), 1038-1046.

[27] N. Shahzad, Some general random coincidence point theorems, New Zealand J. Math., 33(2004), 95-103.

[28] N. Shahzad, Random fixed points of discontinuous random maps, Mathematical and Computer Modelling, 41(2005), 1431-1436.

[29] N. Shahzad, Random fixed points of multivalued maps in Fréchet spaces, Archivum Math., 38(2002), 95-100.

[30] K.K. Tan, X.Z. Yuan, Random fixed-point theorems and approximation in cones, J. Math. Anal. Appl., 185(1994), no. 2, 378-390.

[31] E. Tarafdar, P. Watson, X.Z. Yuan, Jointly measurable selections of condensing Carathéodory set-valued mappings and its applications to random fixed points, Nonlinear Anal., 28(1997) $39-48$.

Received: March 12, 2014; Accepted: June 26, 2014. 
